Ciência e Natura, Santa Maria v.38 n.2, 2016, Mai.- Ago. p. 873 -888

Revista do Centro de Ciências Naturais e Exatas - UFSM

ISSN impressa: 0100-8307 ISSN on-line: 2179-460X

CIÊNCIA'NATURA

\title{
Avaliação da percepção da população gabrielense e de algumas instituições do município quanto ao cumprimento da Política Nacional dos Resíduos Sólidos
}

\author{
English title here Evaluation of the perception of gabrielense population and some \\ institutions in the city as the fulfillment of the National Policy of Solid Wastetitle here
}

\author{
Alexandre Moura Rodrigues, Nara Rejane Zamberlan dos Santos e Cibele Rosa Gracioli \\ Universidade Federal do Pampa - UNIPAMPA \\ alexandremourarodrigues@hotmail.com; narazamberlan@gmail.com; cibelegracioli@gmail.com
}

\begin{abstract}
Resumo
A Politica Nacional de Resíduos Sólidos (PNRS) propõe a prática de hábitos de consumo sustentável. Um dos instrumentos mais importantes dessa política é o conceito de Responsabilidade compartilhada pelo ciclo de vida dos produtos. A Politica Estadual de Resíduos Sólidos/RS dispõe sobre os principios, objetivos, instrumentos e as diretrizes relativas à gestão integrada e ao gerenciamento de resíduos sólidos, as responsabilidades dos geradores e do poder público e aos instrumentos econômicos aplicáveis. Quanto à situação da elaboração dos Planos Municipais de Gerenciamento Integrado de Resíduos Sólidos (PMGIRS/RS), mais da metade dos municípios já elaboraram seus planos. O objetivo do trabalho foi analisar o conhecimento e a percepção da população e de instituições do município de São Gabriel, RS, quanto ao cumprimento da PNRS. A coleta de dados foi efetuada em quatro bairros da cidade: Cidade Nova, Vila Mariana, Independência e Centro. Em cada bairro foram aplicados instrumentos do tipo questionário semiestruturados. Um segundo instrumento foi aplicado junto a nove (9) instituições. Os resultados evidenciaram a importância da destinação adequada dos resíduos sólidos urbanos. A negligência no gerenciamento integrado dos resíduos sólidos somado ao descaso da população e das instituições trazem consequências sociais, econômicas e ambientais, extremamente, negativas ao município.
\end{abstract}

Palavras-chave: Resíduos Sólidos. Gestão integrada. Sustentabilidade. Instituições. População.

\begin{abstract}
The National Solid Waste Policy (PNRS) proposes the practice of sustainable consumption patterns. One of the most important instruments of this policy is the concept of shared responsibility for the lifecycle of products. The State of Solid Waste/RS Policy sets forth the principles, objectives, instruments and guidelines for the integrated management and solid waste management, the responsibilities of producers and the government and to apply economic instruments. As the state of preparation of Municipal Plans for Integrated Management of Solid Waste (PMGIRS / RS) more than half of the municipalities have drawn up their plans. The objective was to analyze the knowledge and perception of the people and institutions in the city of São Gabriel, RS, for adherence to the PNRS. Data collection was conducted in four districts of the city: New Town, Vila Mariana, Independence and Center. In each neighborhood type semi-structured questionnaire instruments were applied. A second instrument was applied with nine (9) institutions. The results showed the importance of proper disposal of municipal solid waste. Negligence in the integrated management of solid waste added to the neglect of people and institutions bring social, economic and environmental consequences extremely negative to the municipality.
\end{abstract}




\section{Introdução}

Segundo dados do Instituto Brasileiro de Geografia e Estatística - IBGE, na última década, a população do Brasil aumentou de 169.799,170 para mais de 190.755,799 milhões de pessoas (IBGE, 2015). No mesmo período, o volume de resíduos cresceu exponencialmente. Esta enorme geração de resíduos e rejeitos, muitas vezes, não é acompanhada de um descarte adequado. De acordo com dados da Associação Brasileira de Empresas de Limpeza Pública e Resíduos Especiais (Abrelpe), só em 2012, dos 64 milhões de toneladas de resíduos produzidos pela população, 24 milhões $(37,5 \%)$ foram enviados para destinos inadequados. Esse descarte inadequado é prejudicial, principalmente, à saúde pública e ao meio ambiente (ABRELPE, 2015). As consequências sociais, econômicas e ambientais do manejo de resíduos sólidos sem prévio e adequado planejamento técnico são uma grande ameaça ao meio ambiente e a saúde da população.

O grande problema que envolve a questão dos resíduos sólidos é o próprio metabolismo que cada sociedade estabelece com os ecossistemas dos quais depende sua reprodução. Lixões e baixo aproveitamento de resíduos sólidos exprimem uma relação doentia entre sociedade e natureza, em cuja base se encontra a maneira como são tanto concebidos, produzidos, distribuídos, consumidos e descartados os produtos quanto geridos os sistemas de coleta e disposição dos remanescentes do consumo. Mesmo que representem forma mais adequada de disposição final dos resíduos que os lixões ou os aterros controlados, os aterros sanitários também são problemáticos, tanto pelos custos quanto pelo espaço que ocupam (ABRAMOVAY, SPERANZA \& PETITGAND, 2013).

A Política Nacional de Resíduos Sólidos (PNRS) (BRASIL, 2010) propõe a prática de hábitos de consumo sustentável e contém instrumentos variados para propiciar o incentivo à reciclagem e à reutilização dos resíduos sólidos, bem como a destinação ambientalmente adequada dos rejeitos. No dia 11 de março, o plenário da Câmara dos Deputados aprovou em votação simbólica um Projeto de Lei que institui a Política Nacional de Resíduos Sólidos impondo obrigações aos empresários, aos governos e aos cidadãos no gerenciamento dos resíduos. No dia 23 de dezembro foi publicado no Diário Oficial da União o Decreto $\mathrm{n}^{\circ}$ 7.404, que regulamenta a Lei $\mathrm{n}^{\mathrm{o}} 12.305$, de 2 de agosto de 2010, que instituiu a Política Nacional de Resíduos Sólidos, criou o Comitê Interministerial da Política Nacional de Resíduos Sólidos e o Comitê Orientador para a Implantação dos Sistemas de Logística Reversa, e dá outras providências. Também no dia 23 foi publicado o Decreto $n^{\circ} 7405$, que instituiu o Programa Pró-Catador, denominado Comitê Interministerial para Inclusão Social e Econômica dos Catadores de Materiais Reutilizáveis e Recicláveis, o Comitê Interministerial da Inclusão Social de Catadores de Lixo criado pelo Decreto de 11 de setembro de 2003, dispõe sobre sua organização e funcionamento, e dá outras providências (BRASIL, 2010).

Um dos instrumentos mais importantes da Política Nacional dos Resíduos Sólidos é o conceito de Responsabilidade compartilhada pelo ciclo de vida dos produtos. Segundo o art. 225 da Constituição Federal de 1988, o meio ambiente ecologicamente equilibrado é direito de todos, bem de uso comum do povo, e também responsabilidade comum de todos (BRASIL, 1988). Assim, fabricantes, importadores, distribuidores, comerciantes, o Estado, o cidadão e titulares dos serviços públicos de limpeza urbana e manejo dos resíduos sólidos são todos responsáveis pela minimização do volume de resíduos sólidos e rejeitos gerados, bem como pela redução dos impactos causados à saúde humana e à qualidade ambiental decorrentes do ciclo de vida dos produtos. 
A responsabilidade compartilhada e 0 Acordo Setorial, contrato firmado entre o poder público e fabricantes, importadores, distribuidores ou comerciantes, e a Logística Reversa, são um conjunto de ações destinadas a viabilizar a coleta e a restituição dos resíduos sólidos ao setor empresarial, para reaproveitamento ou outra destinação final adequada. A lei ainda cria metas importantes para a eliminação dos lixões até 2014, determina a elaboração de um Plano Nacional de Resíduos Sólidos com ampla participação social, contendo metas e estratégias nacionais, prevê a criação de um Sistema Nacional de Informações sobre a Gestão dos Resíduos Sólidos (SINIR), com o objetivo de armazenar, tratar e fornecer informações que apoiem as funções ou processos de gestão dos resíduos prevê a criação de planos de gestão integrada de resíduos sólidos e os planos de gerenciamento de resíduos sólidos nos níveis Federal, estadual e municipal, além de impor que empresas elaborem seus Planos de Gerenciamento de Resíduos Sólidos. (BRASIL, 2010).

A Política Nacional dos resíduos sólidos classifica os resíduos sólidos quanto à origem e, quanto à periculosidade. $\mathrm{O}$ art. 13 da referida lei traz a seguinte classificação:

I - quanto à origem:

a) resíduos domiciliares: os originários de atividades domésticas em residências urbanas;

b) resíduos de limpeza urbana: os originários da varrição, limpeza de logradouros e vias públicas e outros serviços de limpeza urbana;

c) resíduos sólidos urbanos: os englobados nas alíneas a e b;

d) resíduos de estabelecimentos comerciais e prestadores de serviços: os gerados nessas atividades, excetuados os referidos nas alíneas b, e, g, h e j;

e) resíduos dos serviços públicos de saneamento básico: os gerados nessas atividades, excetuados os referidos na alínea c;

f) resíduos industriais: os gerados nos processos produtivos e instalações industriais; g) resíduos de serviços de saúde: os gerados nos serviços de saúde, conforme definido em regulamento ou em normas estabelecidas pelos órgãos do Sisnama e do SNVS;

h) resíduos da construção civil: os gerados nas construções, reformas, reparos e demolições de obras de construção civil, incluídos os resultantes da preparação e escavação de terrenos para obras civis;

i) resíduos agrossilvopastoris: os gerados nas atividades agropecuárias e silviculturais, incluídos os relacionados a insumos utilizados nessas atividades;

j) resíduos de serviços de transportes: os originários de portos, aeroportos, terminais alfandegários, rodoviários e ferroviários e passagens de fronteira;

k) resíduos de mineração: os gerados na atividade de pesquisa, extração ou beneficiamento de minérios;

II - quanto à periculosidade:

a) resíduos perigosos: aqueles que, em razão de suas características de inflamabilidade, corrosividade, reatividade, toxicidade, patogenicidade, carcinogenicidade, teratogenicidade e mutagenicidade, apresentam significativo risco à saúde pública ou à qualidade ambiental, de acordo com lei, regulamento ou norma técnica;

b) resíduos não perigosos: aqueles não enquadrados na alínea a. Parágrafo único. Respeitado o disposto no art. 20, os resíduos referidos na alínea d do inciso I do caput, se caracterizados como não perigosos, podem, em razão de sua natureza, composição ou volume, ser equiparados aos resíduos domiciliares pelo poder público municipal (BRASIL, 2010).

É importante, porém, fazer a distinção entre resíduos e rejeitos. A Lei 12.305/10 em seu art. $3^{\circ}$ parágrafo XV e XVI define:

$\mathrm{XV}$ - rejeitos: resíduos sólidos que, depois de esgotadas todas as possibilidades de tratamento e recuperação por processos tecnológicos disponíveis e economicamente viáveis, não apresentem outra possibilidade que não a disposição final ambientalmente adequada;

XVI - resíduos sólidos: material, substância, objeto ou bem descartado resultante de atividades humanas em sociedade, a cuja destinação final se procede, se propõe proceder ou se está obrigado a proceder, nos estados sólido ou semissólido, bem como gases contidos em recipientes e líquidos cujas particularidades tornem inviável o seu lançamento na rede pública de esgotos ou em corpos d'água, ou exijam para isso soluções técnica ou economicamente inviáveis em face da melhor tecnologia disponível; (BRASIL, 2010)

Além da Lei 12.305/10, aplicam-se aos resíduos sólidos a Política Nacional do Meio Ambiente, as Leis $n^{\circ}$ 11.445 , de 5 de janeiro de 2007, $\mathrm{n}^{\mathrm{o}} 11.107$, de 6 de abril 
de 2005, no 9.795, de 27 de abril de 1999, 9.974, de 6 de junho de 2000 e 9.966 , de 28 de abril de 2000, as normas estabelecidas pelos órgãos do Sistema Nacional do Meio Ambiente (Sisnama), do Sistema Nacional de Vigilância Sanitária (SNVS), do Sistema Unificado de Atenção à Sanidade Agropecuária (Suasa) e do Sistema Nacional de Metrologia, Normalização e Qualidade Industrial (Sinmetro) (BRASIL, 2010 c).

Segundo Jacobi e Besen (2011), embora exista um crescente investimento do governo federal na construção de aterros sanitários e recuperação de energia, centrais de triagem e de compostagem, infraestrutura e capacitação para organizações de catadores, as questões técnicas, econômicas e institucionais dificultam os municípios brasileiros de realizarem uma gestão integrada e sustentável dos resíduos, produzidos pelas próprias municipalidades. A realidade brasileira demanda muito compromisso dos dirigentes municipais na escolha de soluções adequadas de baixo custo, de tecnologias compatíveis com o contexto local e com a implantação da coleta seletiva com remuneração justa do serviço prestado pelos catadores de materiais recicláveis.

Em 16 de abril de 2014, através da Lei Estadual $\mathrm{n}^{\mathrm{o}}$ 14.528, foi instituída a Política Estadual de Resíduos Sólidos do Rio Grande do Sul (RIO GRANDE do SUL, 2014) dispondo sobre os princípios, objetivos, instrumentos e as diretrizes relativas à gestão integrada e ao gerenciamento de resíduos sólidos, incluídos os perigosos, as responsabilidades dos geradores e do poder público e aos instrumentos econômicos aplicáveis. $\mathrm{O}$ Plano Estadual de Resíduos Sólidos do Rio Grande do Sul (PERS-RS) foi elaborado a partir de um convênio entre o Ministério do Meio Ambiente (MMA) e a Secretaria Estadual do Meio Ambiente (SEMA). Finalizado em dezembro de 2014, tem como horizonte os próximos 20 anos e são previstas revisões a cada quatro anos, quando deve ser avaliado o atendimento das metas e ações.

A situação do Rio Grande do Sul, conforme o diagnóstico do Plano Estadual de Resíduos Sólidos-RS demonstra que, 44\% dos municípios do estado cobram por serviços de manejo de Resíduos Sólidos Urbanos (RSU), 18\% não cobram e 38\% não informaram sua atual situação; 45\% dos municípios possuem Iniciativas de Coleta Seletiva, $47 \%$ não possuem e $8 \%$ não informaram; 47\% dos municípios fazem a triagem de resíduos secos recicláveis, 39\% não fazem e 14\% não informaram; 24\% fazem o Tratamento da fração orgânica, $60 \%$ não fazem e $16 \%$ não informaram.

Quanto a Situação da Elaboração dos Planos Municipais de Gerenciamento Integrado de Resíduos Sólidos (PMGIRS) ou Plano Regional de Gerenciamento Integrado de Resíduos Sólidos (PRGIRS) 47\% dos municípios já elaboraram seus PMGIRS ou PRGIRS, $30 \%$ ainda não elaboraram e $23 \%$ dos municípios não informaram sua situação atual. (RIO GRANDE DO SUL, 2014).

Diante do contexto levantado em relação aos municípios no cumprimento da legislação pertinente ao tema o objetivo do trabalho foi analisar o conhecimento e a percepção das instituições e da população do município de São Gabriel, RS quanto ao cumprimento da Politica Nacional dos Resíduos Sólidos.

\section{Metodologia}

O estudo foi desenvolvido no município de São Gabriel localizado na Fronteira-Oeste do Rio Grande do Sul, às margens da BR 290, a 320 quilômetros de Porto Alegre, 290 quilômetros do Porto Internacional de Rio Grande, 300 quilômetros de Uruguaiana/Argentina e 170 quilômetros de Livramento/Uruguai. Próximos ao município estão Rosário do Sul, 64 quilômetros, e Santa Margarida do Sul, 35 quilômetros e 170 quilômetros de Santa Maria (SÃO GABRIEL, 2015).

A coleta de dados foi efetuada em quatro bairros da cidade, considerados os mais populosos, a saber: Cidade Nova, Vila Mariana, Independência e Centro. Em cada bairro foram aplicados instrumentos do tipo questionário semiestruturado. Um segundo instrumento foi aplicado junto a nove (9) instituições as quais foram 
escolhidas por sorteio. Após a coleta os dados foram tabulados e analisados.

\section{Resultados e discussão}

Com base na necessidade de identificar o andamento do estabelecimento do Plano Municipal de Gestão Integrada de Resíduos Sólidos, previsto na Lei 12.305/10, no município de São Gabriel, e em busca da percepção e conhecimento da população se fez necessário uma coleta de dados, do tipo amostragem em quatro bairros da cidade. Dentre os entrevistados houve prevalência do gênero feminino (54\%), com idade média na faixa dos 40 a 49 anos (28\%), tendo como principais atividades: Donas de casa, aposentados, funcionários públicos e comerciantes, entre outras atividades que se repetiram com menos intensidade. $\mathrm{O}$ grau de escolaridade dos respondentes foi, predominantemente, do ensino médio (53\%).

Através da aplicação do instrumento de pesquisa, verificou-se que, a população quando questionada sobre recebimento de orientações, nos últimos 06 (seis) meses, por parte de algum órgão/entidade ou mídia sobre o tema Educação Ambiental, constatou-se que mais de $50 \%$ da população não recebeu a devida orientação. Sendo que em dois bairros, Centro e Vila Mariana, os valores foram equivalentes $(52 \%)$ enquanto os bairros Cidade Nova e Independência os valores foram de $72 \%$ respectivamente (Figura 1). O que demonstra a despreocupação em orientar a população sobre este tema.

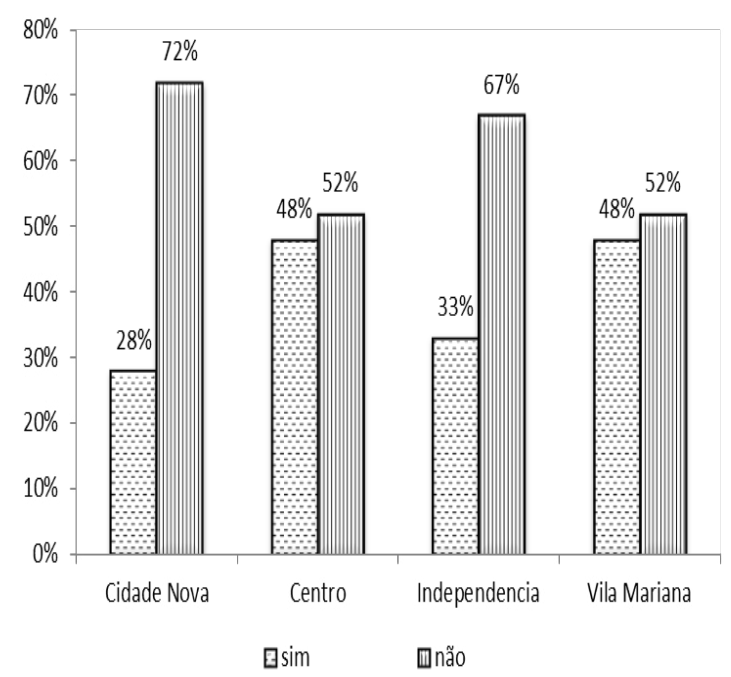

Figura 1 - Resultado das entrevistas relativas ao recebimento de orientações nos últimos 06 meses por parte de algu m órgão/entidade ou mídia sobre Educação Ambiental. São Gabriel, 2015

Considerando que a Educação Ambiental é um dos instrumentos da Política Nacional dos Resíduos Sólidos, faz-se necessário o desenvolvimento de uma consciência ambiental que promova a melhoria da qualidade de vida e das condições ambientais favoráveis a nossa sobrevivência, tanto da atual como das futuras gerações (BUDINOTO, 2009).
A população quando questionada sobre a prática da separação dos resíduos sólidos, respondeu que em torno de $60 \%$ dos entrevistados fazia a separação na sua residência (Figura 2). Os valores positivos foram ultrapassados em todos os bairros enquanto no bairro Centro os entrevistados apresentaram o menor índice de $57 \%$. Em torno de $40 \%$ responderam não separar o lixo. 


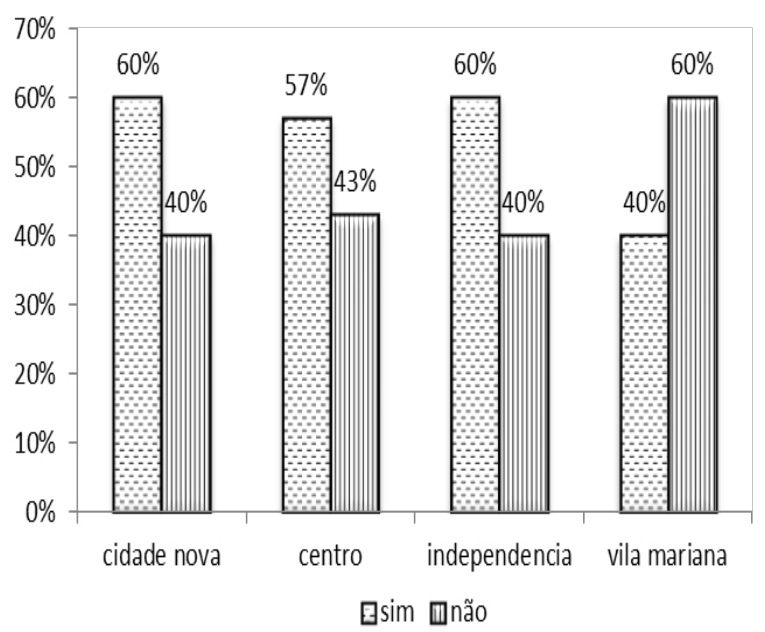

Figura 2 - Posição dos entrevistados quanto a separação entre lixo seco e orgânico. São Gabriel, 2015

Embora a maior parte da população afirme ter o conhecimento do que é a coleta seletiva (mais de $70 \%$ ), uma parcela demonstrou que, embora detenham o conhecimento (Figura 3), não praticam a separação. Este fato pode ser comprovado na Figura 2 cujos valores são contraditórios, com ênfase a Vila Mariana onde $77 \%$ possuem conhecimento (figura 3 ), mas somente $40 \%$ (figura 2) possui esta prática.

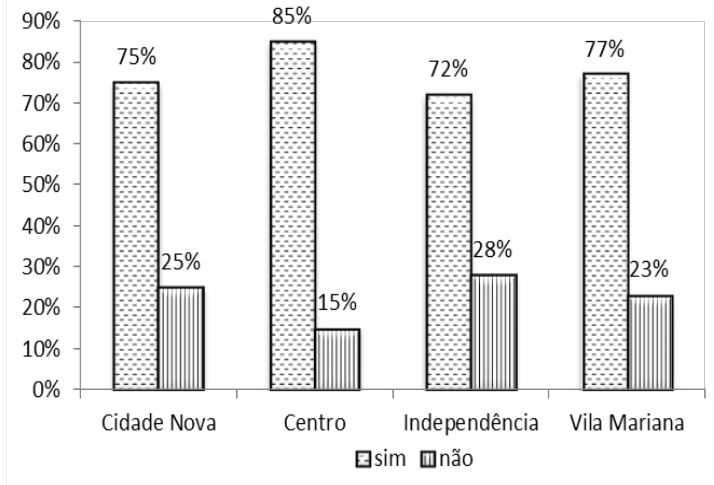

Figura 3 - Conhecimento sobre o conceito de coleta seletiva. São Gabriel, 2015

A coleta seletiva ou o processo de separação e recuperação de materiais recicláveis dos Resíduos Sólidos Urbanos é definida por Bringhenti (2004) como:

a etapa de coleta de materiais recicláveis presente nos resíduos sólidos urbanos, após sua separação na própria fonte geradora, seguido de seu acondicionamento e apresentação para coleta em dias e horários pré-determinados, ou mediante entrega em Postos de Entrega Voluntária, em Postos de Troca, a catadores, a sucateiros ou a entidades beneficentes (BRINGHETI, 2004 pag. 14).
As difusões do conceito de Desenvolvimento Sustentável vêm fazendo com que a população se preocupe cada vez mais com os diversos aspectos do meio ambiente ecologicamente equilibrado. Alguns desses aspectos afetam os canais de distribuição reversos como: disposição do lixo urbano devido aos seus efeitos nocivos, e baixa porcentagem de reciclagem como é o caso do lixo orgânico que pode ser transformado em 
composto (fertilizante) para utilização na agricultura (RODRIGUES et al, 2002).

Para Grimberg e Blauth (1998), existe uma certa confusão em torno do conceito de coleta seletiva. É comum as pessoas entenderem a coleta como sinônimo de separação de materiais descartados ou como reciclagem. A coleta seletiva de resíduo não é a separação de materiais em si, mas uma etapa entre esta separação e o processo de reciclagem. Este termo aplica-se ao recolhimento diferenciado destes materiais já separados nas fontes geradoras, alternados com a coleta regular. Deve ficar claro, portanto, que não adianta separar materiais se não houver um sistema de recolhimento especial, que permita que os materiais separados sejam recuperados para reciclagem, reuso, ou compostagem.

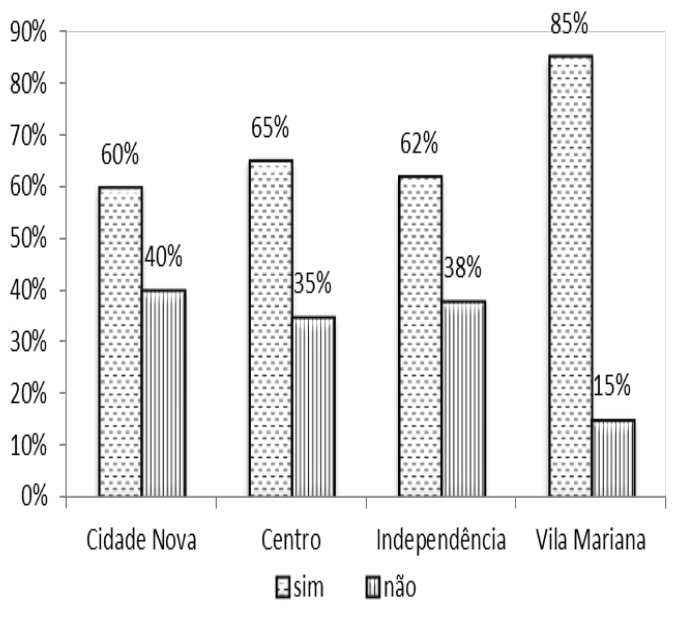

Em relação à destinação dos resíduos sólidos, a maioria da população (mais de 60\%) mostrou-se conhecedora do fato de que o destino final de seus resíduos após a coleta regular no município é um vazadouro a céu aberto ou Lixão (Figura 4a). Quanto à posição dos entrevistados quanto a destinação, a opinião predominante é a de que os resíduos sólidos urbanos não têm uma destinação ambientalmente adequada no município, com índices que variaram entre $80 \%$ e $90 \%$ (Figura 4b). Este resultado denota haver uma preocupação por parte dos cidadãos com as questões ambientais que envolvem a gestão dos resíduos sólidos a cargo da municipalidade.

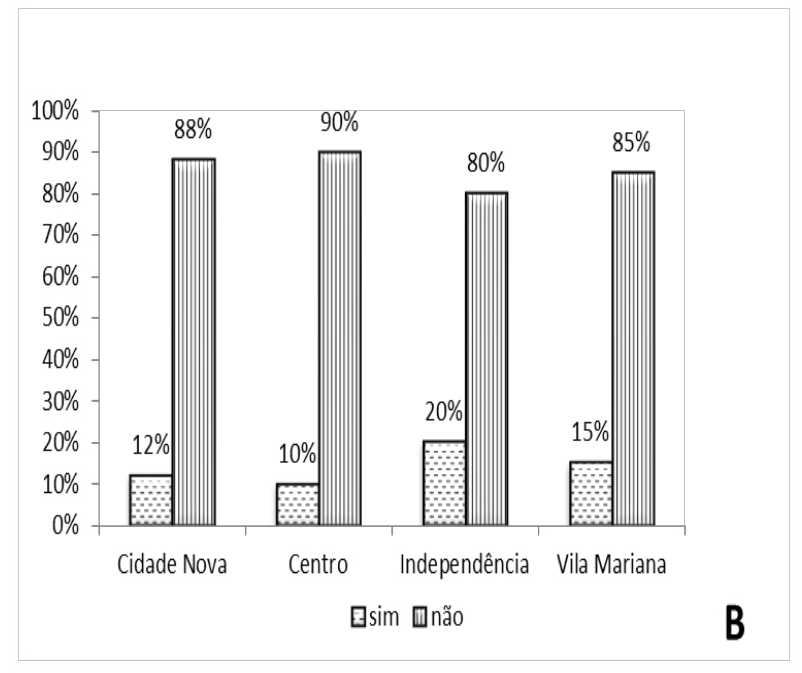

A

Figura 4A - Conhecimento pelos entrevistados sobre a destinação dos resíduos sólidos No município. Figura 4B - Posição dos entrevistados quanto a destinação ser adequada ou não. São Gabriel, 2015

Segundo Brollo (2001), a produção de resíduos sólidos urbanos nas cidades brasileiras é um problema impossível de ser evitado, pois sua ocorrência além de ser diária, ainda depende da densidade demográfica e do nível de desenvolvimento econômico local. O sistema de limpeza urbana, portanto, não deve limitar-se em afastar o lixo da área urbana e sim dar um destino ambiental e sanitário adequado ao mesmo.
Schmitz (2014) esclarece que lixão é o local onde ocorre a disposição final de resíduos sobre o solo, sem qualquer cuidado ou técnica, caracterizando-se pela falta de medidas de proteção ao meio ambiente e à saúde pública.

Aterro controlado é uma categoria intermediária entre lixão e o aterro sanitário, visando apenas à cobertura dos resíduos com uma camada de terra, grama, ou argila, 
selada com manta impermeável. Porém, a maioria dos aterros controlados são apenas células adjacentes ao lixão, de forma remediada, evitando a proliferação de vetores e o seu carreamento pelas águas pluviais. E por fim, o mesmo autor evidencia que o aterro sanitário é a melhor técnica de disposição de resíduos sólidos urbanos no solo, pois, antes de iniciar a disposição do lixo, o terreno é preparado por meio de nivelamentos de terra, selamento da base com argila e mantas de PVC, evitando a contaminação do solo.

Quando questionados sobre a destinação adequada, todos concordaram que os resíduos sólidos urbanos tenham correta destinação, porém, quando indagados sobre qual o método de disposição final seria o mais adequado e menos prejudicial ao meio ambiente, há uma grande confusão entre os conceitos de aterro sanitário e aterro controlado, evidenciando o desconhecimento da população sobre a questão. Pode-se considerar, ainda, a existência de uma pequena parcela da população que não julga ser um problema a disposição de resíduos em um lixão a céu aberto no município (Figura 6).

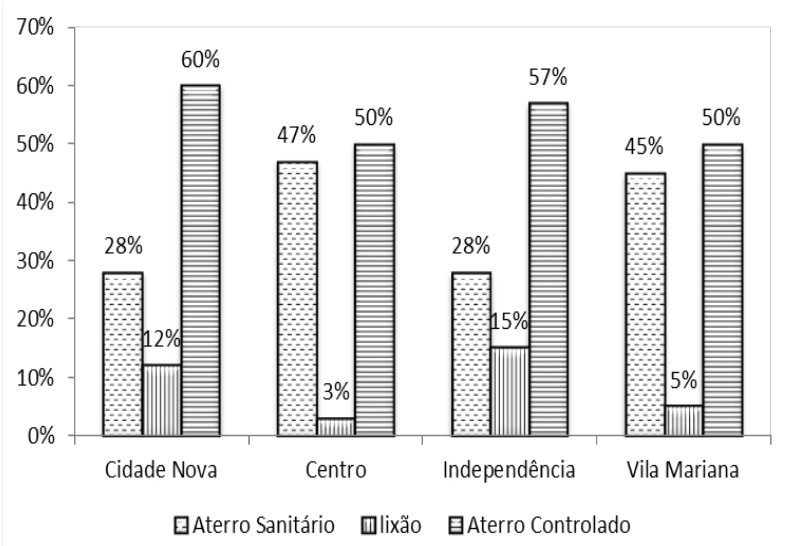

Figura 6 - Posição dos entrevistados sobre a destinação adequada dos RSU. São Gabriel 2015

O aterro controlado é apontado em todos os bairros entrevistados com valores que variam de $50 \%$ a $60 \%$. O aterro sanitário aparece como segunda opção com valores correspondentes a $45 \%$ a $47 \%$ no Centro e Vila Mariana respectivamente e valores de $28 \%$ na Cidade Nova e Independência. O lixão é citado nos quatro bairros com ênfase ao bairro Independência (15\%) e Cidade Nova (12\%).

A Logística Reversa é conceituada na Política Nacional dos Resíduos Sólidos em seu artigo $3^{\circ}$ parágrafo XII como (BRASIL, 2010):

\begin{abstract}
XII - logística reversa: instrumento de desenvolvimento econômico e social caracterizado por um conjunto de ações, procedimentos e meios destinados a viabilizar a coleta e a restituição dos resíduos sólidos ao setor empresarial, para reaproveitamento, em seu ciclo ou em outros ciclos produtivos, ou outra destinação final ambientalmente adequada (BRASIL, 2010 pag. 11).
\end{abstract}

Em relação à Logística Reversa o desconhecimento varia de $70 \%$ a $92 \%$ dos entrevistados. O bairro Centro demonstra que $30 \%$ da população reconhece esta técnica, seguida pelo bairro Vila Mariana (25\%), conforme Figura 7. 


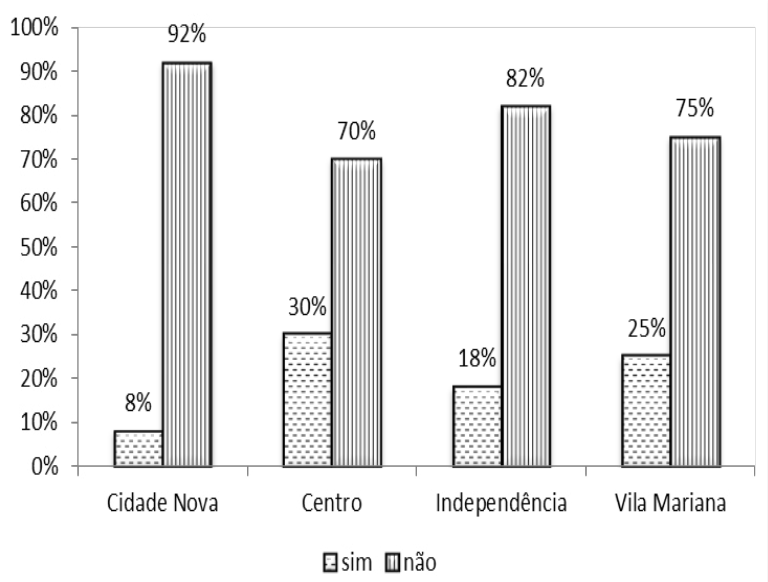

Figura 7 - Posição dos entrevistados quanto ao conhecimento do conceito de Logística Reversa. São Gabriel, 2015

Segundo Silva e Colmenero (2010), a Logística Reversa (LR) consiste em uma atividade responsável pelo retorno dos materiais do ponto de consumo ao ponto de origem, agregando valor de diferentes naturezas ao produto retornado.

Para Klassen (2012) este tema é muito importante para a sociedade contemporânea, pois, com os produtos retornando ao ciclo produtivo, há economia no uso da energia, além da preservação ambiental e a economia dos recursos naturais.

Diante deste quadro, é preocupante saber que o conhecimento do conceito de logística reversa é ignorado por mais da metade da população estudada. No caso específico de um dos quatro bairros, quase a totalidade dos cidadãos afirmaram desconhecer o que é logística reversa. $\mathrm{O}$ índice dos que declaram conhecer o conceito de LR não ultrapassou os $30 \%$ (figura 7).

O Plano Municipal de Gerenciamento Integrado de Resíduos Sólidos (PMGIRS), além de ser um dos instrumentos da Política Nacional dos Resíduos Sólidos (PNRS), Lei 12.305/10, é uma obrigatoriedade. Esta lei determinou o prazo de agosto de 2012, para que os municípios tivessem apresentado seus planos e, assim, tivessem acesso aos recursos da União destinados a gestão e o gerenciamento de resíduos sólidos. Esses planos devem ter metas de redução, reutilização, coleta seletiva e reciclagem, entre outras, com o objetivo de reduzir a quantidade de rejeitos encaminhados para disposição final, ambientalmente, adequada. Este plano contém o conjunto de ações voltadas para a busca de soluções para os resíduos sólidos gerados pelo município, considerando as dimensões políticas, econômicas, ambiental, cultural e social (BRASIL, 2010).

A inércia do poder público em cumprir a legislação encontra o apoio, muitas vezes, dos próprios cidadãos que sem espírito de coletividade, não cobram de seus governantes o cumprimento de suas responsabilidades. O grande problema é quando o cidadão desconhece a legislação $\mathrm{e} \quad \mathrm{o}$ dever do administrador público em cumprir a lei. Segundo a Figura 8, nos quatro bairros amostrados a resposta "Não sei" atinge índices médios de $60 \%$, seguido da resposta "Não" com valores variáveis de $32 \%$ a $38 \%$. Na Vila Mariana observou-se o total desconhecimento (100\%) em relação à necessidade de existência do PMGIRS. 


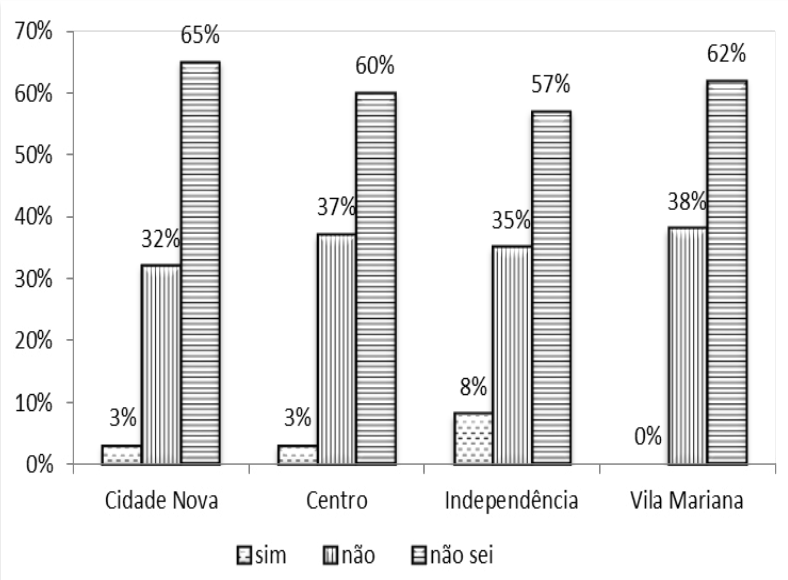

Figura 8 - Conhecimento sobre a necessidade da existência de um PMGIRS nos municípios brasileiros. São Gabriel, 2015

Segundo Reidler e Günther (2002), a simples existência de uma lei não é suficiente para que a mesma seja conhecida e, muito menos, cumprida. Para que isto aconteça é necessária uma ampla divulgação da lei junto à população em geral, para a qual, teoricamente, a mesma seria destinada. Se não há divulgação, não haverá conhecimento e, tampouco, conscientização.

A interpretação dos dados vem de encontro à situação dos quatro bairros de São Gabriel amostrados, onde os valores de "não" e "não sei" se aproximam de $100 \%$.

Conforme Oliveira (2013), é necessário o estabelecimento de metas para o desenvolvimento das ações e programas necessários para a concretização do PMGIRS. O plano deve ser construído com metas de longo, médio e curto prazo, considerando que as soluções deverão ser consolidadas de forma gradual conforme a disponibilidade de recursos de cada município.

Atualmente, o município de São Gabriel encontra-se com seu lixão fechado, utilizado apenas para transbordo. Os resíduos gerados no município são encaminhados para aterros sanitários licenciados. Porém, durante a etapa de pesquisa de dados, o município encontrava-se com seu lixão funcionando. Segundo reportagem publicada em Zero Hora no dia $1^{\circ}$ de agosto de 2014, São Gabriel ainda era um dos cinco municípios no estado do Rio Grande do Sul que ainda possuía lixão, juntamente com os municípios de Santa Margarida do Sul, Ipiranga do Sul, Viamão e Uruguaiana. No caso específico do município de Santa Margarida do Sul, o lixo era enviado para São Gabriel. Quando houve a emancipação do município de Santa Margarida do Sul, foram sancionadas leis municipais em ambas as cidades e coube à São Gabriel o encargo de receber os resíduos. Diante desta realidade, os entrevistados foram questionados sobre o fato de o município receber o lixo gerado em outro município, sendo que, no local de pesquisa os resíduos eram descartados de maneira irregular. Os munícipes em sua maioria não concordam com esse procedimento, com ênfase a Vila Mariana, Cidade Nova e Independência. Por unanimidade os quatro bairros são contrários a essa prática com valores varáveis de 72\% (centro), $80 \%$ (Independência), 82\% Cidade Nova e 88\% Vila Mariana (Figura 9). 


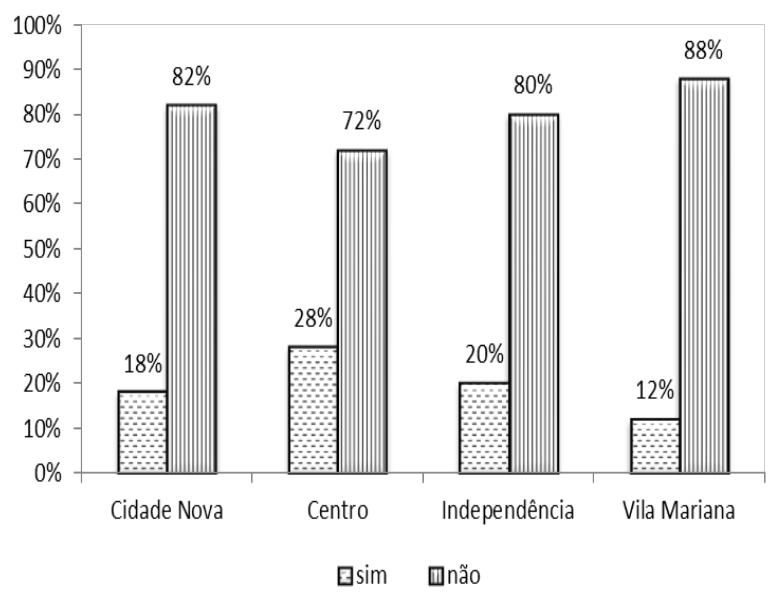

Figura 9 - Posição dos entrevistados quanto à concordância do município de São Gabriel receber resíduos gerados em uma cidade(s) vizinha(s). São Gabriel, 2015

Segundo Oliveira (2002), para que sejam estabelecidos planos, programas, projetos e ações no sentido de obter os resultados pretendidos, é necessário que sejam tomadas algumas iniciativas preliminares indispensáveis. É importante que sejam identificados e reunidos os atores sociais participantes do processo. No caso dos resíduos sólidos de um município, há que considerar o posicionamento de cada um dos envolvidos, enfim, todos os que, de alguma forma, participarão efetivamente na apreciação, decisão e na manutenção do pretendido, com vistas à sustentação política e logística das diversas atividades. Assim, a participação da população não deve estar restringida ao processo de avaliação dos impactos ambientais, mas deve também estar presente na definição da qualidade ambiental e na determinação de mecanismos reguladores e estabelecimento das propostas das políticas ambientais. $\mathrm{O}$ apoio da sociedade à questão das políticas ambientais sensibiliza e estimula os governos à implementação de programas de despoluição e de proteção ambiental.

Um segundo instrumento foi aplicado junto as Instituições/Entidades onde as mesmas ao serem questionadas a respeito da realização de um diagnóstico operacional para compreender o cenário atual da gestão dos resíduos sólidos do município, servindo como base para o planejamento e a implementação de um sistema de gestão de resíduos sólidos com sustentabilidade, apresentaram posições diferentes sendo que 33,33\% entendem já haver sido realizado e a mesma porcentagem respondeu nada haver sido cumprido. Há de se perguntar em que base os entrevistados responderam que já houve um diagnóstico operacional detectado em $33,00 \%$ ?

Para Monteiro (2001)

pode-se considerar o gerenciamento integrado do lixo quando existir uma estreita interligação entre as ações normativas, operacionais, financeiras e de planejamento das atividades do sistema de limpeza urbana, bem como quando tais articulações se manifestarem também no âmbito das ações de limpeza urbana com as demais políticas públicas setoriais. Nesse cenário, a participação da população ocupará papel de significativo destaque, tendo reconhecida sua função de agente transformador no contexto da limpeza urbana (MONTEIRO, 2001 pag. 8).

Quanto ao plano de varrição manual de cidade que incluem determinantes como: qualidade do serviço desejado; testes de produtividade; extensão das vias a serem varridas e mão de obra a ser utilizada também houve posições diferentes sendo que, 33,33\% consideram que 50,00\% tem sido cumprido, e o mesmo valor ponderou que $25,00 \%$ esta sendo cumprido na sua totalidade.

Para Mesquita e Ferreira (2008) 
Os serviços de limpeza urbana, quando bem planejados e executados, são a garantia de uma gestão eficiente para os resíduos sólidos urbanos, incluindo aí a diminuição dos gastos da Prefeitura com os mesmos. Tais serviços além de manter a limpeza e a higienização de áreas públicas, têm importância como ação de saneamento e de preservação da saúde. Eles interferem diretamente no controle do meio ambiente e, portanto, na saúde do homem, demandando assim, soluções planejadas e tecnicamente adequadas a cada realidade (MESQUITA e FERREIRA, 2008 pag. 3).

Segundo Lopes (2003), além da importância da geração de empregos, a limpeza de vias e logradouros públicos é importante para garantir uma cidade mais limpa.

Quanto à coleta e transporte dos resíduos (considerando remoção regular do lixo acondicionado, coletado, transportado, tratado e encaminhado para a disposição final) $44,44 \%$ das instituições consideraram que o município cumpre, aproximadamente, 25,00\%, do esperado, 33,33\% das instituições consideraram que o município cumpre, aproximadamente, $50,00 \%$ e $22,22 \%$ consideraram que o município cumpre aproximadamente, $75,00 \%$ a coleta e o transporte de resíduos de forma adequada. Estes valores demonstram que não somente a população não detecta conhecimento, como também as instituições mais importantes do município.

Segundo Amaecing e Ferreira (2008), a preocupação com a coleta dos resíduos sólidos deixou de ser uma mera obrigação de afastamento dos mesmos dos locais de geração, pois os resíduos sólidos, quando dispostos de maneira incorreta em vias públicas, comprometem a estética das cidades e a saúde da população. Nesse contexto, com o intuito de minimizar esse impacto visual e evitar a proliferação de vetores, cabe à administração pública das cidades fornecerem os serviços de coleta com regularidade e competência onde haverá o envolvimento da administração municipal com a comunidade, com o intuito de minimizar os perigos decorrentes do lixo e propiciar, do ponto de vista do saneamento, a higienização e a preservação da saúde para toda a população.

Quanto à ocorrência de distinção entre a coleta e transporte dos resíduos domiciliares, públicos e de pequeno comércio dos resíduos dos grandes geradores, bem como os referentes à saúde e construção civil, a posição das instituições mantiveram-se diferenciadas. Enquanto 33,33\% julgaram que o município cumpre, aproximadamente, $50,00 \%$ a distinção entre transporte e coleta de resíduos o mesmo valor estimou que o município cumpre $25,00 \%$, ainda, 22,22\% consideraram que nada foi cumprido e $11,11 \%$ consideraram que foi cumprido totalmente. Há de se perguntar qual a razão de tamanha distorção na análise de órgãos/instituições que detém o conhecimento e a possibilidade de julgamento?

Quanto à situação do município referente à recuperação de materiais (triagem, reciclagem e compostagem), a posição das entidades dividiu-se em $33,33 \%$ das instituições que consideram que o município cumpre, aproximadamente, $50,00 \%$ e, outros $33,00 \%$ que consideram que é cumprido, aproximadamente, 25,00\% da recuperação de materiais, enquanto as outras instituições dividiram-se em 22,22\% que consideram que o município cumpre, aproximadamente, $75,00 \%$ e $11,11 \%$ que consideram que nada foi cumprido.

Para Santos et al (2006), a implantação de Usinas de Triagem e Compostagem apresentam vantagens para o município do ponto de vista econômico. Do ponto de vista ambiental, reduz drasticamente a necessidade de lixões, que contaminam os lençóis freáticos, atraem insetos, pragas e causam doenças. São economicamente interessantes para os municípios, pois traz divisas por meio da reciclagem, compostagem e arrecadação do ICMS ecológico, além de minimizar problemas ambientais.

Quanto à situação do tratamento e disposição final, considerando tratamento como uma série de procedimentos físicos e biológicos que tem por objetivo diminuir a carga poluidora no meio ambiente, reduzir os impactos negativos sanitários do homem e, também o beneficiamento econômico do resíduo e a destinação final como a última fase do processo, 33,33\% das instituições pesquisadas consideram que aproximadamente 50,00\% foi cumprido, enquanto, outras 33,33\% das instituições 
ponderam que, aproximadamente, $25,00 \%$ foi cumprido seguidas de $22,22 \%$ das instituições que julgam que nada foi cumprido e outras $11,11 \%$ que julgam que foi cumprido, aproximadamente, $75,00 \%$ do tratamento e disposição final dos Resíduos Sólidos Urbanos do município.

Para Brollo (2001), o gerenciamento inadequado dos resíduos sólidos geram sérios problemas para as comunidades, pois, resultam ao mesmo tempo em riscos indesejáveis à saúde pública e à degradação ambiental. As ações técnicas para a gestão dos resíduos devem ser norteadas pelos aspectos relacionados à preservação ambiental e á saúde publica, levando em consideração, também, os aspectos sociais, estéticos, econômicos e administrativos.

Considerando que a destinação mais indicada no cenário brasileiro para a destinação final dos resíduos sólidos são os aterros sanitários. As instituições pesquisadas julgaram, outra vez, a situação do município de São Gabriel de maneira divergente. Novamente dividiram-se entre $33,33 \%$ que consideram que o município cumpre, aproximadamente, $75,00 \%$, com sua obrigação de dar um destino final adequado aos resíduos sólidos, ou seja, um aterro sanitário e outras 33,33\% que consideram que é cumprido, aproximadamente, 50,00\%. Houve uma parcela menos significativa de instituições que julgam que nada foi cumprido $(22,22 \%)$ e $11,11 \%$ pondera que o município cumpre, aproximadamente, $25,00 \%$ de suas obrigações com a questão abordada. É lamentável essa disparidade entre as instituições, devido a função que cumprem no município, pois, teoricamente deveriam ser os grandes incentivadores do cumprimento da legislação.
Quanto à questão da existência ou não, no município, do estabelecimento de formas de financiamento do sistema de gestão de resíduos sólidos (Ex: arrecadação de receita para a gestão de resíduos sólidos por meio de taxas embutidas no Imposto Predial e Territorial Urbano (IPTU), as instituições mostraram uma maior unidade de opinião, onde, 44,44\% julgam que o município cumpre totalmente $(100 \%)$, ou seja, segundo estas instituições existe uma cobrança sobre a sociedade gabrielense, na forma de impostos, para o financiamento do sistema de gerenciamento de resíduos sólidos. Outras duas parcelas de $22,22 \%$ de instituições dividiram-se entre as que consideram que nada foi cumprido, ou, que não existe tal cobrança, e as que consideram que aproximadamente $25,00 \%$ é cumprido, sinalizando que se a cobrança existe, não é muito significativa. Outra parcela menor, $11,11 \%$ considera que aproximadamente 50,00\% é cumprido. Este fato demonstra que o cidadão em geral não têm a preocupação em verificar os valores que são pago caso contrário, saberiam responder corretamente.

Quanto à questão de como pode ser classificada a situação do PMGIRS no município de São Gabriel 33,33\% das instituições questionadas consideram que o plano foi cumprido, aproximadamente $50,00 \%$, ou seja, o PMGIRS está em fase de elaboração no município, sendo que metade do processo está concluído. Outra parcela de 33,33\% das instituições considera que, aproximadamente, $25,00 \%$ foi cumprido, seguidas por $22,22 \%$ das instituições considerando que nada foi cumprido, o que corresponde a realidade atual do município, pois, não possui um PMGIRS e 11,11\% julgam que, aproximadamente, $75,00 \%$ do processo de elaboração do plano foi cumprido (Figura 10). 


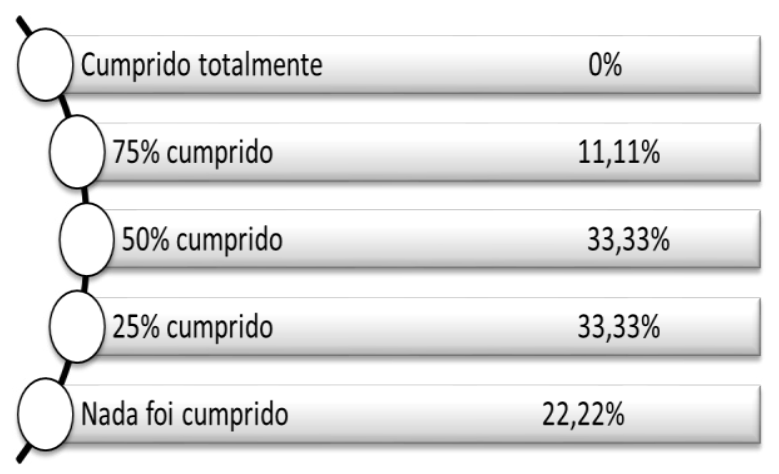

Figura 10 - Situação do PMGIRS de São Gabriel, segundo as instituições pesquisadas no município. São Gabriel, 2015

O fato de apenas $22,22 \%$ das instituições do município demonstrarem que têm o conhecimento da realidade atual do PMGIRS (figura 10) é preocupante. Se as instituições que representam a sociedade nos seus diversos segmentos, em sua maioria, não sabem se a legislação está sendo cumprida por seus administradores públicos, e por outro lado, a maioria da população demonstra desconhecer (Figura 8) a importância dos PMGIRS, uma vez que a Política Nacional de Resíduos Sólidos determina que os Municípios devam estabelecer seus próprios Planos Municipais, a quem caberá cobrar o cumprimento da Lei?

\section{Conclusões}

Pela observação dos aspectos analisados, percebe-se que o conhecimento e a percepção das instituições e da população do município de São Gabriel, RS quanto ao cumprimento da Política Nacional dos Resíduos Sólidos, são muito limitados. A falta de ciência e de cobrança por parte da sociedade enfraquece qualquer legislação por mais relevante e importante que seja sua essência. $\mathrm{O}$ fato de tratar-se de regulamento relativamente recente (2010), também pode ser levado em consideração, o que não justifica a falta de informação e de evolução do nível de cidadania, no sentido de promover mudanças, a partir de uma maior conscientização da sociedade.

Apesar de a legislação ambiental brasileira ser considerada avançada e bem elaborada, a exemplo da Constituição Brasileira de 1988, que dedica um capítulo inteiro ao meio ambiente, nota-se que o problema está em um primeiro momento, na aplicação da lei e em um segundo momento na fiscalização por parte da população e dos diversos órgãos públicos, uma vez que a própria Constituição impõe como obrigação da sociedade e do Estado a preservação e a defesa do ambiente. Vale ressaltar que a ação da mídia no papel de levar informação ao cidadão, também foi considerada baixa. Apesar de sua grande capacidade de formação de opinião, é lamentável o fato de não estar engajada na transformação e na melhoria da qualidade de vida da sociedade. Isto é resultado de um conjunto de fatores políticos, econômicos e culturais.

Em virtude do que foi mencionado, é imprescindível que o poder público se conscientize que a Educação Ambiental é um importante instrumento de mobilização social da comunidade. A mudança de hábitos e comportamentos necessários para a implantação de projetos relacionados aos resíduos sólidos, como a coleta seletiva, só pode ser possível com a atuação crítica e consciente de indivíduos e grupos de forma contínua e permanente. As campanhas educativas devem instigar a participação efetiva e ativa da coletividade de forma que haja uma real percepção da crise ambiental, obrigando a diminuição da geração de resíduos, estimulando o consumo sustentável, a reutilização com menor número de desperdício e a reciclagem dos resíduos gerados, introduzindo-os novamente no sistema produtivo para que se transformem em novos produtos.

A pesquisa evidenciou a importância da destinação adequada dos resíduos sólidos urbanos. A 
negligência no gerenciamento integrado dos mesmos somados ao descaso da população e das instituições trazem consequências sociais, econômicas e ambientais extremamente negativas ao município. Além de onerar desnecessariamente o erário, transportando-se os resíduos para outra localidade, por exemplo, põe-se em risco a saúde de seus cidadãos.

Acredita-se que essa pesquisa deva ser aplicada em outros municípios, de modo a assegurar uma visão mais abrangente, da percepção da sociedade, das instituições representativas desta sociedade e do pleno conhecimento da legislação referente aos resíduos sólidos. O assunto está em voga e é um dos grandes desafios da humanidade. $\mathrm{O}$ aumento populacional crescente, o processo de expansão e urbanização das cidades, a demanda por recursos naturais e a geração diária dos resíduos sólidos urbanos são realidades que precisam ser enfrentadas pelos municípios de maneira criativa, cabendo aos gestores locais encontrar soluções eficientes e eficazes na minimização dos impactos ambientais.

\section{Referências}

BANKS-LEITE, L. As questões lingüísticas na obra de Piaget: apontamentos para uma reflexão crítica. In: (Org.). Percursos piagetianos. São Paulo: Cortez, 1997. p. 207-223.

ABRAMOVAY, Ricardo; SPERANZA, J. S.; PETITGAND, C. Lixo zero : gestão de resíduos sólidos para uma sociedade mais próspera. Planeta sustentável. São Paulo: Instituto Ethos; 2013.

AMAECIN, Maicyla A. Paez; FERREIRA Osmar Mendes. Serviços de Coleta de Lixo Urbano na Região Central de Goiânia: Estudo de Caso. 2008. 39 f. Universidade Católica de Goiás, Departamento de Engenharia, Engenharia Ambiental, Goiânia, 2008.

ASSOCIAÇÃO BRASILEIRA DE EMPRESAS DE LIMPEZA PÚBLICA E RESÍDUOS ESPECIAIS ABRELPE. Panorama dos resíduos sólidos no Brasil, 2012. São Paulo: Abrelpe, 2015.

BRASIL. Constituição (1988). Constituição da República Federativa do Brasil. Brasília, DF: Senado, 1988. Disponível em http://www.senado.gov.br/legislacao /const/con1988/CON1988 05.10.1988 /index.shtm Acesso em 05 dez 2014.
BRASIL. LEI 12.305, de 2 de agosto de 2010. Institui a Política Nacional de Resíduos Sólidos; altera a Lei no 9.605, de 12 de fevereiro de 1998; e dá outras providências. Disponível em $<$ http://www. planalto.gov.br/ccivil_03/_ato2007-

2010/2010/lei/112305.htm> Acesso em 02 dez 2014.

BRINGHETI, Jaqueline. Coleta Seletiva de Resíduos Sólidos Urbanos: Aspectos Operacionais e de Participação da População São Paulo. Departamento de Saúde Ambiental/USP. 2004.

BROLLO, M. J.; Metodologia Automatizada para a seleção de áreas para a disposição de resíduos sólidos: Aplicação na Região Metropolitana de Campinas (SP). São Paulo. Departamento de Saúde Ambiental/USP. 2001.

BUDINOTO, Vanessa Minuzzi. Web Artigos. A Importância da Reciclagem. Você contribui

com o meio ambiente e com a sua própria vida? Disponível em http:/www.webartigos.com/articles/16750/1/aimportancia-dareciclagem/pagina1.html. Acessado em 16 mai 2015.

COSTA, Letícia, Cinco municípios no RS ainda descartam detritos da coleta urbana em lixões.

ZERO HORA 01 ago 2014 Disponível em: 23http://zh.clicrbs.com.br/rs/noticias/noticia/2014/08/cinc o-municipios-no-rs-ainda-descartam-detritos-da-coletaurbana-em-lixoes-4565107.html. Acesso em 23 dez 2014.

GRIMBERG, E.; BLAUTH, P. (Coords.). Coleta seletiva. São Paulo: Pólis, 1998.

INSTITUTO BRASILEIRO DE GEOGRAFIA E ESTATÍSTICA - IBGE. Censo demográfico, 2010. Rio de Janeiro: IBGE, 2015.

JACOBI, P. R.; BESEN, G. R. Gestão de resíduos sólidos em São Paulo: desafios da sustentabilidade, São Paulo (SP). Estudos Avançados, São Paulo, v.25, n.31, p.135158, 2011. Disponível em $<$ http://www.scielo.br/scielo.php?script=sci_arttext\&pid= S0103 40142011000100010\&lng=pt\&nrm=iso $>$. acessos em 16 abr 2015.

KLASSEN, C.; A Importância Da Logística Reversa Na Sociedade Contemporânea. Curitiba. Universidade Tuiuti Do Paraná. 2012.

LOPES, Adriana Antunes; Estudo da Gestão e do Gerenciamento Integrado dos Resíduos Sólidos Urbanos no Município de São Carlos (SP) São Carlos. Escola de Engenharia de São Carlos/USP; 2003.

MESQUITA, V. de Castro; FERREIRA, Osmar Mendes. Análise do Desempenho dos Serviços de Varrição na Região Central de Goiânia. Goiânia. Departamento de 
Engenharia - Engenharia Ambiental/Universidade Católica de Goiás; 2008.

MONTEIRO et al., José H. P. Manual de Gerenciamento Integrado de Resíduos Sólidos. Rio de Janeiro: IBAM, 2001.

OLIVEIRA, Artur S. Dias de; Método Para a Viabilização da Implantação de Plano de Gerenciamento Integrado de Resíduos Sólidos: O Caso do Município do Rio Grande - Rs. Florianópolis. Programa De PósGraduação Em Engenharia De Produção/ Universidade Federal De Santa Catarina. 2002.

REIDLER, N. M. V. Longo; GÜNTHER, W. M. Risso. Percepção da População Sobre os Riscos do Descarte Inadequado de Pilhas e Baterias Usadas. XXVIII Congresso Interamericano de Ingeniería Sanitaria y Ambiental. 2002. 27 a 31 out. Cancún, México.

RIO GRANDE DO SUL. LEI N ${ }^{\circ} 14.528$, DE 16 DE ABRIL DE 2014. Institui a Política Estadual de Resíduos Sólidos e dá outras providências.

RODRIGUES, D. F; RODRIGUES, Gisela Gonzaga; LEAL, José Eugenio; PIZZOLATO, Nélio Domingues. Logística Reversa - Conceitos e Componentes Do Sistema. In: XXII Encontro Nacional de Engenharia de Produção Curitiba - PR. 2002. 23 a 25 de out. pp. 1-8. Disponível em: http://www.abepro.org.br/biblioteca/ENEGEP2002_TR1 1_0543. Pdf. Acessos em: 03 mar. 2015.

SANTOS, Rodrigo Couto et al. Usinas de Compostagem de Lixo como alternativa viável à problemática dos lixões no meio urbano. Enciclopédia Biosfera, N.02, MG. 2006.

SÃO GABRIEL, Prefeitura Municipal de São Gabriel RS. Disponível em: $<$ http://www.saogabriel.rs.gov.br/2013/conheca/localizac ao.html. Acessos em: 16 fev 2015.

SCHMITZ, G. A.; A Lei 12.305/2010 e a Questão Dos Resíduos Sólidos No Município De Alegrete - RS. Santa Maria Especialização Em Educação Ambiental/UFSM. 2014.

SILVA, Mayara Cristina Ghedini da; COLMENERO, João Carlos. A logística reversa como forma de desenvolvimento sustentável e competitivo das empresas. IN: ENCONTRO DE ENGENHARIA E TECNOLOGIA DOS CAMPOS GERAIS, 5 [Internet]; 2010 Outubro 1922; Paraná, Brasil. 2002. Disponível em: http://www.revistas2.uepg.br/index.php/exatas/article/vie wFile/1221/2655.pdf. Acesso em 24 jan 2015. 